\title{
Blasones intelectuales, lecturas regionales, derivas nacionales. Aportes santafesinos a la historiografía académica argentina (1893-1938)/
}

\author{
Intellectual blazons, regional readings, national derivations. \\ Santa Fe's contributions to the academic historiography \\ in Argentina (1893-1938)
}

\author{
María Gabriela Micheletti \\ UCA IDEHESI/CONICET \\ Rosario, Argentina
}

En este artículo se pasa revista a los historiadores de la provincia argentina de Santa Fe que fueron miembros de la Junta de Historia y Numismática Americana, institución fundada en 1893 y transformada en Academia Nacional en 1938. En particular, se procura indagar si esa pertenencia significó un aporte a los estudios de historiografía provincial, en el ámbito de una institución interesada en construir una versión liberal y canónica del pasado nacional.

PAlabras ClaVE: Historiografía; Historiografía provincial; Santa Fe (Argentina); Junta de Historia y Numismática Americana; Historiadores.

This article focuses on the historians of the province of Santa Fe (Argentina) who were members of the Junta de Historia y Numismática Americana, institution founded in 1893 and turned into a National Academy in 1938. Especially, it inquiries into the possible contribution to local historiographical studies, considering their membership to an institution interested in building a liberal and canonical version of the national past.

KeYwords: Historiography; Provincial historiography; Santa Fe (Argentina); Junta de Historia y Numismática Americana; Historians. 
La Junta de Historia y Numismática Americana es en la Argentina la institución sabia por excelencia. Reúne en su seno hombres destacados del país [...] Esta selección de valores intelectuales que la componen es la característica que la distingue [...] Ella es para sus miembros, un hogar espiritual y blasón de su vida de estudiosos [...]

(Enrique de Gandía: La Junta de Historia y Numismática Americana. Breve noticia histórica, Buenos Aires, Imprenta de la Universidad, 1935, 3 y 48)

\section{Introducción}

Los orígenes de la historiografía erudita argentina se ubican hacia mediados del siglo XIX, en torno a la aparición de la primera versión de la Historia de Belgrano (1857) de Bartolomé Mitre. ${ }^{1}$ Los debates entre este político historiador y Vicente F. López, autor de una Historia de la República Argentina en diez tomos (1883-1893), alimentaron una discusión sobre los modos y métodos para abordar el pasado y contribuyeron a otorgarle densidad teórica a la incipiente práctica historiográfica.

La versión erudita de la historia sostenida por Mitre obtuvo realidad institucional con la Junta de Historia y Numismática Americana (JHNA), cuya fecha de fundación en 1893 señala un hito en el proceso de nacimiento y consolidación de la historiografía liberal académica argentina. Transformada en Academia Nacional de la Historia (ANH) en 1938, dicha institución fue reflejo del afianzamiento de la Historia como disciplina y del paso de la erudición a la ciencia —en sintonía con el proceso de configuración del historiador profesional durante las primeras décadas del siglo XX-, y obtuvo del Estado apoyo y recursos para elaborar un relato hegemónico del pasado, heredero de la historiografía liberal, que se plasmó en la publicación de la Historia de la Nación Argentina (19361950).

En tanto la corporación iba alcanzando estructura y rasgos más definidos, la posibilidad de integrarla se volvió condición y, a la vez, fuente de prestigio. Por un lado, ser admitido implicaba un reconocimiento a la tra-

1 En la tercera edición de esta obra, de 1876-1877, su autor le incorporó una fundamental introducción sobre la «sociabilidad argentina». Mitre, 1967, I, 11-76. 
yectoria previa, y era resultado de los vínculos forjados con quienes a partir de entonces se volverían pares. Pero, por otro lado, significaba un plus de autoridad, y la legitimación en tanto que historiador, en una época en la que aún no existían títulos habilitantes para la práctica historiográfica. De ella formó parte la mayoría de los principales referentes de la historiografía nacional de esos años, aun cuando el accionar desplegado desde el Instituto de Investigaciones Históricas de la Facultad de Filosofía y Letras de Buenos Aires (1921), ${ }^{2}$ le sirviera de contrapunto. Desde ambas instituciones, como así también, desde el ámbito de la docencia universitaria, un núcleo de profesionales de la Historia — que se consideró heredero de Mitre - fue el responsable de llevar adelante la renovación historiográfica que dio forma a la Nueva Escuela Histórica (NEH) a partir de la segunda década del siglo XX. ${ }^{3}$

Al contemplarse desde los primeros tiempos una doble categoría para los miembros de la Junta — de número y correspondientes—, una pléyade de historiadores provenientes de las provincias argentinas pudo compartir el honor de formar parte de ese círculo de sociabilidad intelectual de elite.

A partir de un enfoque regional, este artículo indaga la trayectoria y la labor historiográfica, en tanto que miembros de la institución, de aquellos intelectuales e historiadores originarios de la provincia de Santa Fe que formaron parte de la JHNA. Su pertenencia a una de las instituciones de Historia más importantes del país, los señala a priori, durante el período bajo estudio, como los principales exponentes de la historiografía académica y erudita de esa próspera provincia del litoral argentino. ${ }^{4}$ Se procura determinar qué perfil tuvieron dichos historiadores, cuáles fueron sus temas de estudio y su desempeño en la Junta, en qué condiciones o circunstancias se incorporaron a ésta, y en qué medida significaron un aporte al

2 Este Instituto, dirigido por Emilio Ravignani, se estableció sobre la base de la Sección de Historia de la Facultad (1905). De él formaron parte destacados historiadores, algunos de los cuales integraron también la JHNA, como el mismo Ravignani, Luis María Torres y Carlos Correa Luna. Pompert de Valenzuela, 1995, 252-260.

3 Devoto y Pagano, 2009, 139-200. Los hombres de la NEH (Carbia, Levene, Molinari, Ravignani, Torres) han sido considerados el primer grupo de historiadores profesionales de la Argentina.

4 La provincia de Santa Fe, bañada por el río Paraná y ubicada en la región pampeana, sobrevivió en la primera mitad del XIX en una situación apremiante, durante el periodo de las guerras civiles. Pero desde mediados de dicho siglo, experimentó un significativo desarrollo gracias a la explotación agrícola y a la radicación masiva de inmigrantes, en el marco del modelo económico agroexportador adoptado por la Argentina. Gallo, 1983. 
avance de los estudios de historiografía provincial, en el ámbito de una institución interesada en construir y proveer una versión canónica del pasado nacional. ${ }^{5}$

\section{La Junta de Historia y Numismática Americana}

Su historia se remonta a 1893, año en que bajo la figura tutelar de Mitre comenzó a reunirse un núcleo de destacados intelectuales. Dedicada en un inicio a la numismática, en 1901 se regularizó su existencia con el nombre de JHNA. Mitre la presidió hasta su fallecimiento (1906), siendo luego presidida por Enrique Peña, Antonio Dellepiane, Ramón Cárcano, Martiniano Leguizamón, Carlos Correa Luna y Ricardo Levene (quien gestionó su transformación en Academia). En 1901 fue organizada con miembros de número (un máximo de cuarenta), que al incorporarse debían leer un trabajo de su autoría, y correspondientes (residentes fuera de la Capital Federal), que podían asistir a las reuniones con voz pero sin voto y eran eximidos del trabajo de incorporación. Como fines de la institución, se fijaron: «fomentar los estudios que su nombre indica y establecer relaciones entre las personas que se ocupan de ellos dentro o fuera del país». ${ }^{6}$

El accionar de la Junta ha sido diferenciado en dos periodos: el de predominio de la numismática y de la tradición elitista de la tertulia académica, con definición de los rasgos institucionales (1893-1918), y el de innovación y proyección institucional con predominio de los temas históricos (1919-1937). ${ }^{7}$ Para justipreciar la importancia de la Junta, no debe olvidarse quiénes fueron sus iniciadores y el momento en el que surgió. Mitre, su fundador, que fuera presidente de la Argentina en el «período de la organización nacional», como historiador logró articular un discurso tan exitoso sobre el origen de la nación que fue seguido por años por sucesivas generaciones de historiadores. En cuanto al momento de la creación, en la Argentina de entresiglos (XIX-XX) se vivió un clima de preocupación por

5 Un conjunto de investigaciones recientes han estudiado al núcleo de intelectuales e historiadores vinculados al proceso de desarrollo de la historiografía académica en sus respectivos países y/o regiones. Vg., Peiró Martín, 1998, 165-196; Sánchez-Prieto, 1987, 193-226; Pasamar Alzuria y Peiró Martín, 1991, 135-162, y Vázquez, 2001, 709-718.

6 BJHNA, III, 1926, 232

7 ANH, 1995, I, 20. 
la definición de la identidad nacional, que alcanzó un punto culminante hacia el Centenario de Mayo (1910). Estas circunstancias «marcaron muy profundamente la consustanciación de la JHNA con la historia de la nación», ya que «no se trató, únicamente, de estudiar esa historia, de investigar sobre ella, también se participó en su construcción». ${ }^{8}$

\section{Numerarios y correspondientes santafesinos}

Compartiendo un rasgo común a la mayoría de las instituciones de carácter corporativo, la JHNA procuró salvar del olvido la actuación de sus miembros. En esta tarea, el Boletín (1924) cumplió un papel significativo y actualmente constituye un valioso material para acceder al conocimiento del funcionamiento interno de la institución a partir de 1901, cuando comenzó a dejarse registro en actas de las reuniones, ya que éstas fueron publicadas a posteriori en el Boletín. Además, a partir de 1924 fueron publicadas las memorias anuales del presidente y la mayoría de las conferencias. A través de estas fuentes es posible asomarse puertas adentro de la Junta para recabar interesantes datos sobre los intelectuales que pasaron por ella, los que dan indicios del proceso de consagración que se fue operando sobre sus personas, y que bien sintetizan las palabras escritas en 1935 por el secretario de la Junta, Enrique de Gandía, citadas en el epígrafe inicial. Aquellos provincianos que la integraron, vieron por ello aumentar su reconocimiento en su propio medio, y es un lugar común, por ejemplo, que en las biografías de intelectuales santafesinos, se recalque esa membresía como si, por sí sola, constituyera garantía de sus cualidades como historiador.

En la provincia de Santa Fe, fueron seis los miembros de número, y catorce los correspondientes (dos llegaron a ser también numerarios), que entre 1893 y 1938 se incorporaron a la Junta. A continuación se presenta, en forma de cuadro, ${ }^{9}$ el listado de los miembros originarios (por nacimiento o adopción) de Santa Fe que la integraron, y se consigna el título o tema de las conferencias que pronunciaron y de las cuales se tiene conocimiento.

8 Ravina, 1995, 24.

9 Elaboración propia a partir de los datos consignados en ANH, 1995, I, Apéndice, 330-357. 


\section{MIEMBROS DE NÚMERO}

\begin{tabular}{|c|c|c|}
\hline Datos biográficos & Nombramiento & Temas de conferencias ${ }^{10}$ \\
\hline $\begin{array}{l}\text { Gabriel Carrasco } \\
\text { (Rosario, 1854 / } \\
\text { Buenos Aires, } \\
\text { 1908) }\end{array}$ & 1901 & $\begin{array}{l}\text { Los reyes en América en el siglo XIX } \\
\text { (3/7/04, L). } \\
\text { Movimiento de población en Argentina, 1903- } \\
\text { 1904. Natalidad, mortalidad, censo electoral } \\
\text { (7/8/04, L). } \\
\text { Consideraciones sobre la Argentina como } \\
\text { nación macrocéfala y otros aspectos estadísticos } \\
\text { (17/9/05, L). } \\
\text { El valor monetario de la higiene pública. } \\
\text { El crecimiento de la población de la República } \\
\text { Argentina. 1895-1906. } \\
\text { Los progresos demográficos del Rosario. 1887- } \\
\text { 1906 (5/5/07). } \\
\text { Datos demográficos de la población argentina, } \\
\text { 1905-1906 (16/6/07, L). } \\
\text { Los colores de la bandera (25/7/1907, L). } \\
\text { Aspectos del comercio de América Latina } \\
\text { (3/11/1907). } \\
\text { Sobre el adelanto material de veinte naciones de } \\
\text { América (1/12/1907, L). }\end{array}$ \\
\hline $\begin{array}{l}\text { Estanislao } \\
\text { Zeballos } \\
\text { (Rosario, 1854 / } \\
\text { Inglaterra, 1923) }\end{array}$ & 1901 & $\begin{array}{l}\text { El sistema histórico que adoptará en su obra } \\
\text { Historia General del Río de la Plata } \\
(7 / 11 / 1909, \mathrm{~L}) \text {. }\end{array}$ \\
\hline $\begin{array}{l}\text { José María de } \\
\text { Iriondo (Santa Fe, } \\
\text { 1871/ Buenos } \\
\text { Aires, 1940) }\end{array}$ & 1901 & \\
\hline $\begin{array}{l}\text { David Peña } \\
\text { (Rosario, 1862 / } \\
\text { Buenos Aires, } \\
\text { 1930) }\end{array}$ & 1906 & $\begin{array}{l}\text { La Real Audiencia Pretorial y la Primera Junta } \\
\text { del Gobierno Patrio (25/10/1906, I). } \\
\text { Drama histórico sobre Dorrego (4/7/1909, L). } \\
\text { Estudio sobre la personalidad de San Martín de } \\
\text { la obra Flor y lava de José Martí (7/11/1915, L). } \\
\text { Introducción de Historia de las leyes de la } \\
\text { Nación Argentina (3/9/1916, L). } \\
\text { Alberdi, Sarmiento y Mitre. Estudio biográfico } \\
\text { comparado (3/06/1917, L). } \\
\text { De Caseros al 11 de Septiembre (12/9/1920, L). } \\
\text { Vida y obra de José de San Martín. Su difusión } \\
\text { (16/7/1921, L y proyecto de ley). }\end{array}$ \\
\hline
\end{tabular}

10 Siglas utilizadas: Conferencia de Incorporación (I), Lectura (L), Junta Filial Rosario (JFR) 
MIEMBROS DE NÚMERO (continuación)

\begin{tabular}{|l|c|l|}
\hline Datos biográficos & Nombramiento & Temas de conferencias \\
\hline Rodolfo Rivarola & 1916 & La historia ante la política y la filosofía \\
(Rosario, 1857 / & & $(20 / 05 / 1917$, I). \\
Buenos Aires, & & Mitre estadista (25/6/1921, sesión especial de \\
1942) & & homenaje a Mitre). \\
& & $\begin{array}{l}\text { Ciclos de ideas-fuerzas en la Historia Argentina } \\
(17 / 10 / 1931) \text {. }\end{array}$ \\
& & La confraternidad argentino-brasileña \\
& & $(9 / 11 / 1935)$. \\
\hline Juan Álvarez & \multirow{2}{*}{1935} & Rosario bajo el gobierno autónomo de \\
(Gualeguaychú, & & Estanislao López (I). \\
Entre Ríos, 1878 / & & Rosario bajo el gobierno autónomo de \\
Rosario, 1954) & & Estanislao López, 1822-1838 (9/5/1936, L). \\
\hline
\end{tabular}

\section{MIEMBROS CORRESPONDIENTES}

\begin{tabular}{|l|c|l|l|}
\hline Datos biográficos & Nombram. & Correspondiente en & Conferencias \\
\hline $\begin{array}{l}\text { Ramón Lassaga } \\
\text { (Santa Fe, 1858 / } \\
1921)\end{array}$ & 1901 & Santa Fe & \\
\hline $\begin{array}{l}\text { Juan Álvarez } \\
\text { (Gualeguaychú, } \\
\text { Entre Ríos, 1878 / } \\
\text { Rosario, 1954) }\end{array}$ & 1915 & $\begin{array}{l}\text { Santa Fe } \\
\text { Junta Filial Rosario }\end{array}$ & $\begin{array}{l}\text { Valores aproximados de } \\
\text { algunas monedas } \\
\text { hispanoamericanas desde la } \\
\text { reforma de 1497 hasta la de } \\
1772 . \text { (I). } \\
\text { El factor individual en la } \\
\text { historia (20/10/1928). } \\
\text { Orígenes del Rosario } \\
(21 / 6 / 1931, \text { L en JFR). }\end{array}$ \\
\hline $\begin{array}{l}\text { Félix Barreto } \\
\text { (La Paz, Entre } \\
\text { Ríos, 1874 / } \\
\text { Santa Fe, 1948) }\end{array}$ & 1925 & Santa Fe & \\
\hline $\begin{array}{l}\text { Manuel Cervera } \\
\text { (Dolores, Bs. As., } \\
\text { 1863 / Santa Fe, } \\
\text { 1956) }\end{array}$ & 1925 & Santa Fe & \\
\hline
\end{tabular}


MARÍA GABRIELA MICHELETTI

MIEMBROS CORRESPONDIENTES (continuación)

\begin{tabular}{|c|c|c|c|}
\hline Datos biográficos & Nombram. & Correspondiente en & Conferencias \\
\hline $\begin{array}{l}\text { Nicolás } \\
\text { Amuchástegui } \\
\text { (Córdoba, 1877 / } \\
\text { Lomas de } \\
\text { Zamora, Bs. As., } \\
\text { 1954) }\end{array}$ & 1929 & Junta Filial Rosario & $\begin{array}{l}\text { El brigadier general } \\
\text { D. Benjamín Virasoro. } \\
\text { Su misión histórica. I parte } \\
\text { (25/7/1931, L en JFR) y } \\
\text { II parte (14/8/1931, L en } \\
\text { JFR). }\end{array}$ \\
\hline $\begin{array}{l}\text { José Luis } \\
\text { Busaniche } \\
\text { (Santa Fe, } 1892 \text { / } \\
\text { Buenos Aires, } \\
\text { 1959) }\end{array}$ & 1929 & $\begin{array}{l}\text { Santa Fe } \\
\text { Junta Filial Rosario }\end{array}$ & $\begin{array}{l}\text { Política interprovincial 1829- } \\
1831 \text { (I). } \\
\text { Artigas en los orígenes } \\
\text { autonómicos de Santa Fe } \\
\text { (19/7/30, L en JFR). } \\
\text { Santa Fe y el Uruguay. 1820- } \\
1830 \text { (20/7/1930, L en JFR). }\end{array}$ \\
\hline $\begin{array}{l}\text { Antonio Cafferata } \\
\text { (Rosario, } 1875 \text { / } \\
\text { 1932) }\end{array}$ & 1929 & Junta Filial Rosario & $\begin{array}{l}\text { Don Celedonio Escalada } \\
(12 / 8 / 1929, \text { L en JFR). }\end{array}$ \\
\hline $\begin{array}{l}\text { Calixto Lassaga } \\
\text { (Rosario, } 1857 \text { / } \\
\text { 1954) }\end{array}$ & 1929 & Junta Filial Rosario & $\begin{array}{l}\text { Determinación del sitio en } \\
\text { que se izó por primera vez la } \\
\text { bandera argentina (18/5/1930, } \\
\text { L en JFR). }\end{array}$ \\
\hline $\begin{array}{l}\text { Julio Marc } \\
\text { (Rosario, } 1884 \text { / } \\
\text { 1965) }\end{array}$ & 1929 & Junta Filial Rosario & $\begin{array}{l}\text { La guerra y la paz en la } \\
\text { numismática americana } \\
\text { colonial (18/10/1930, L en } \\
\text { JFR). }\end{array}$ \\
\hline $\begin{array}{l}\text { Francisco } \\
\text { Santillán } \\
(1890 / 1953)\end{array}$ & 1929 & Junta Filial Rosario & $\begin{array}{l}\text { ¿Fue incendiada la Capilla } \\
\text { del Rosario? (29/6/1930, L en } \\
\text { JFR). }\end{array}$ \\
\hline $\begin{array}{l}\text { Federico Zeballos } \\
\text { (Rosario, } 1860 \text { / } \\
\text { Alta Gracia, } \\
\text { Córdoba, 1944) }\end{array}$ & 1932 & Junta Filial Rosario & Orígenes de Rosario (I). \\
\hline $\begin{array}{l}\text { Guillermo } \\
\text { Furlong (Villa } \\
\text { Constitución, } \\
1889 \text { / Buenos } \\
\text { Aires, 1974) }\end{array}$ & $\begin{array}{c}1936 \\
(1938: \\
\text { miembro } \\
\text { de número } \\
\text { de ANH) }\end{array}$ & Santa Fe & $\begin{array}{l}\text { Joaquín Millás esteta y } \\
\text { filósofo (I). }\end{array}$ \\
\hline
\end{tabular}


BLASONES INTELECTUALES, LECTURAS REGIONALES, DERIVAS NACIONALES

MIEMBROS CORRESPONDIENTES (continuación)

\begin{tabular}{|l|c|l|l|}
\hline Datos biográficos & Nombram. & Correspondiente en & Conferencias \\
\hline $\begin{array}{l}\text { Juan Jorge } \\
\text { Gschwind (San } \\
\text { Carlos Sur, 1900 / } \\
\text { Rosario, 1956) }\end{array}$ & 1936 & Junta Filial Rosario & $\begin{array}{l}\text { La cuestión de límites con } \\
\text { Chile y los Pactos de Mayo } \\
(5 / 8 / 1933, \text { L en JFR). }\end{array}$ \\
\hline $\begin{array}{l}\text { Faustino Infante } \\
\text { (Rosario, 1891 / } \\
\text { 1969) }\end{array}$ & 1936 & Junta Filial Rosario & \\
\hline
\end{tabular}

Presentada la nómina, es posible establecer algunas relaciones. En el aspecto profesional, casi todos los santafesinos incorporados durante los primeros tiempos poseían formación jurídica (la excepción fue Iriondo, hacendado y numismático). ${ }^{11}$ Recién a partir de 1925 la ocupación se diversificó un tanto, aún cuando los abogados continuaron siendo mayoría. Estas características profesionales de los santafesinos no constituían una singularidad dentro de la corporación, ya que en ella también predominaban los abogados, aún cuando la diversidad era mayor. El cuadro con las profesiones de los miembros santafesinos entre 1893 y 1938 es el siguiente:

\begin{tabular}{lc} 
Profesión & Cantidad \\
\hline Abogados & 13 \\
Periodistas & 1 \\
Sacerdotes & 1 \\
Pedagogos & 1 \\
Militares & 1 \\
Publicistas & 1 \\
Hacendados & 1
\end{tabular}

11 Los datos biográficos incluidos en este artículo provienen de: Abad de Santillán, 1967. 
En cuanto al rango etario, los santafesinos se incorporaron como numerarios con una edad promedio de 47 años, y los correspondientes, con un promedio de 49 años. La mayoría ingresó en la década de los 40 años:

Edad al ingresar Miembros de número Miembros correspondientes

\begin{tabular}{lll}
\hline 30 a 39 años & 1 & 4 \\
40 a 49 años & 3 & 4 \\
50 a 59 años & 2 & 3 \\
60 a 69 años & - & 1 \\
70 a 79 años & - & 2
\end{tabular}

Ahondar en las circunstancias de la incorporación y en las respectivas trayectorias, permite distinguir distintos momentos de contacto entre los contextos de producción provincial y nacional, tomando como observatorio de análisis a la JHNA. Si se tiene en cuenta que ésta jugó su rol en la elaboración de una versión de la historia nacional, que aggiornó y proyectó la tradición liberal hasta bien entrado el siglo XX, no es irrelevante considerar qué cabida se dio a los historiadores provinciales en ese proceso y a qué mecanismos recurrieron éstos para transferir sus visiones regionales o locales del pasado a esa construcción historiográfica académica.

\section{Los primeros años: santafesinos de relieve «nacional»}

El año 1901, el de la organización institucional, figuran como miembros los rosarinos Gabriel Carrasco y Estanislao Zeballos (de número), y los santafesinos José María de Iriondo (de número) y Ramón Lassaga (correspondiente). ${ }^{12}$ En 1906, se sumó el rosarino David Peña (de número).

Para esos primeros tiempos las fuentes son más escasas, ya que no han sido publicadas en el Boletín las disertaciones, ni se conocen las circunstancias de las incorporaciones anteriores a 1901. Tampoco es probable que al comienzo se pronunciasen conferencias de incorporación, condición que estableció el Estatuto de 1902, y que sí cumplimentó Peña.

12 En la provincia de Santa Fe, sus dos principales ciudades presentan notas distintivas que refuerzan el contraste entre la tradicional y burocrática capital Santa Fe, y la nueva, pujante y cosmopolita Rosario. 
El análisis de las actas iniciadas en 1901, no obstante, brinda interesantes detalles acerca de la actuación y los aportes de estos primeros santafesinos a una institución que se encontraba en plena etapa de organización, y permite comprobar que desempeñaron, en especial Carrasco y Peña, un rol de importancia en ese proceso. Si se deja a un lado a Iriondo, miembro por un lapso muy breve y cuya figura intelectual e historiográfica no es comparable a la de los otros exponentes citados, ${ }^{13}$ puede constatarse que los santafesinos que se incorporaron a la Junta durante esos primeros años eran hombres de reconocida trayectoria pública a nivel provincial y nacional, y que ocuparon un lugar de significación dentro de la vida política y del movimiento intelectual de fines del siglo XIX y principios del XX.

Todos integraban la elite dirigente de Santa Fe, si bien, en los casos de Carrasco, Zeballos, Lassaga y Peña, no se tratara de personas de recursos económicos, sino que fueron su capital intelectual y sus vinculaciones sociales, los que contribuyeron a ubicarlos entre los notables de la época.

En cuanto a su actuación e influencia como productores culturales, trascendieron - en especial, Carrasco, Zeballos y Peña— los límites de su provincia, y lograron proyección nacional, sobre todo desde su radicación en Buenos Aires. Esta ciudad centralizaba la mayor parte de las empresas culturales, casas editoriales y publicaciones y, en ella, los intelectuales y su producción parecían adquirir visibilidad. La residencia en Buenos Aires fue la que les permitió a Carrasco, Zeballos y Peña ingresar como miembros de número, pero también la que desdibujó sus orígenes provincianos.

Hacia 1901, Gabriel Carrasco — reconocido por sus estudios estadísticos- era director de la Oficina Demográfica Argentina y del Boletín Demográfico Argentino. En años anteriores había desempeñado varios cargos ejecutivos y legislativos municipales y provinciales, y había sido responsable del censo santafesino de 1887 y del nacional de 1895. Había escrito ya la mayor parte de su obra, que entre libros y artículos superaba el centenar de títulos. En 1897 había publicado los Anales de la ciudad del Rosario de Santa Fe. ${ }^{14}$ Como miembro de la Junta hasta su fallecimiento en 1908, se caracterizó por su acción y su compromiso con la institución. Tuvo un alto índice de asistencia a las sesiones y a él se debe la redacción

13 Coleccionista numismático y director del museo histórico de su ciudad, Iriondo pertenecía a una familia eminente de la elite santafesina. Aunque su nombre fue incluido en la lista de miembros elaborada a fines de 1901, no aparece en la nómina de junio de 1903, debido a no haber asistido a ninguna reunión durante 1902. BJHNA, III, 216, 219 y 234.

14 Micheletti, 2009, 84-88. 
del proyecto para el primer estatuto, aprobado en 1902..$^{15}$ Además, se distinguió como conferencista asiduo, sobre temas de demografía histórica y estadística, aplicadas a la realidad argentina, deteniéndose en una única oportunidad en este tipo de análisis con respecto a su ciudad natal, Rosario.

Estanislao Zeballos era, para principios del siglo, una figura destacada de la política argentina. Su radicación en la capital del país databa de sus años estudiantiles, aunque de una visita a su provincia natal surgieron las impresiones que plasmó en 1883 en La rejión del trigo (sic), relato histórico-literario en el que presentaba una semblanza de la historia de la inmigración y colonización agrícola santafesina. Diputado, convencional constituyente, y ministro de Relaciones Exteriores y de Justicia e Instrucción Pública, de este cargo se valió para conseguirle por parte del gobierno algunos beneficios a la Junta. ${ }^{16}$ Vinculado desde joven al periodismo, ofreció a sus compañeros de la Junta su afamada Revista de Derecho, Historia y Letras (1898-1923), la que acogió la colaboración de la mayor parte de los miembros. Ésta se constituyó así en un ámbito de interacción historiográfica informal entre quienes compartían relaciones formales e institucionalizadas al interior de la Junta. ${ }^{17}$ Polifacético y erudito, Zeballos fue autor de cientos de artículos sobre gran variedad de temas. ${ }^{18}$ Aunque poco asiduo a las reuniones, aprovechó sus apariciones por la Junta para ilustrar sobre libros raros y documentos poco conocidos, y en su única exposición registrada explicó el sistema histórico que adoptaría en su Historia General del Río de la Plata, que no llegó a concretar. ${ }^{19}$ La permanencia de Zeballos en la Junta, pese a sus largas ausencias, y como contrapartida la rápida prescindencia de Iriondo, evidencian bien el comportamiento ambivalente de la institución, que optaba por disculpar a quienes le aportaban un significativo capital simbólico, y reflejan su doble carácter —explicado antes- de dadora y demandante de prestigio.

15 BJHNA, III, 230 y 232-233.

16 Ibidem, IV, 1927, 366 y 373.

17 Ibidem, III, 212. Como señaló Leguizamón como presidente de la Junta en 1923, Zeballos «no era de los concurrentes más asiduos, pero su pensamiento estuvo siempre al lado de nosotros, con el aplauso generoso y estimulador para todas las iniciativas de la institución, desde las columnas de su revista.» BANH, XVIII, 1945, 391.

18 Zeballos responde al modelo del «historiador erudito», sabio y crítico, que con su revista cumple un rol similar al que desempeñó Gabriel Monod en Francia con la publicación de necrologías de historiadores en la Revue Historique, ya que también él publica biografías y necrologías de intelectuales (varios, pertenecientes a la Junta). Dumoulin, 2003, 150-162.

19 BJHNA, III, 243-244 y 258, y V, 1928, 212. 
Autor dramático, egresado y profesor de la Universidad de Buenos Aires, David Peña vio envuelta su incorporación (1906) en una polémica, debido al libro que había publicado poco antes sobre Facundo Quiroga. ${ }^{20}$ Realizando una operación de revisión histórica que, sin embargo, no lo llevaba a enfrentarse con la tradición liberal (en una línea en la que ya habían incursionado autores como Adolfo Saldías y Ernesto Quesada), Peña se animaba a contradecir la tesis de Domingo F. Sarmiento y hacía la defensa del caudillo riojano. ${ }^{21} \mathrm{Su}$ obra confrontaba con las interpretaciones dominantes sobre el caudillismo y ubicaba a Quiroga en la senda del sistema constitucional argentino. ${ }^{22}$ A pesar de la oposición despertada ${ }^{23}$ la postura de Peña contribuyó a darle notoriedad, y el año 1906 debe ser considerado clave para su proyección como historiador. La revista de Zeballos publicó un avance de su libro y unas elogiosas apuntaciones biográficas, en las que se reconocía a Peña el mérito de romper «el silencio y la inacción» en la historia nacional, que se mantenía «paralizada» en las obras de Mitre y López. ${ }^{24} \mathrm{La}$ incorporación de Peña indica que la Junta no era del todo ajena a la renovación que -impulsada sobre todo desde las provincias- se estaba gestando desde fines del siglo XIX, orientada a revisar la visión hegemónica sobre la época de las guerras civiles y los caudillos. Unos años antes que Peña había ingresado a la Junta, como correspondiente por Santa Fe, Ramón Lassaga, un precursor de esa línea reivindicatoria a través de su Historia de López (1881). ${ }^{25}$ Es decir que la Junta, si bien tributaria de la tradición liberal, acogió desde sus orígenes a historiadores que en mayor o menor medida la cuestionaron, aún sin posicionarse en oposición a ella.

20 Peña, 1906.

21 Nora Pagano incluye a Peña entre los posibles «revisionistas» anteriores al revisionismo histórico argentino, quienes plantearon la mayoría de los tópicos desarrollados luego por éste, pero sin romper con la tradición liberal. Devoto y Pagano, 2009, 203-204. Variables como los espacios de formación, y los vínculos que mantuviera Peña con liberales pero opositores al centralismo porteño, como Juan B. Alberdi, pueden conjeturarse como posibles explicaciones a esa forma de hacer historia.

22 Buchbinder, 2005, 42-43.

23 BJHNA, IV, 329-330, 332 у 346.

24 «Juan Facundo Quiroga», Revista de Derecho, Historia y Letras, XXIV, 1906, 498-513.

25 Micheletti, 2010, 91-118. En la reciente obra de Devoto y Pagano se denomina género reivindicatorio al utilizado por algunos escritores de fines del siglo XIX — comprendido Lassaga—, quienes elaboraron «alegatos "documentados" que con distintas modulaciones tendían a difundir o restituir la memoria de episodios o personajes injustamente invocados o ignorados en las narraciones disponibles». Devoto y Pagano, 2009, 53-60. 
David Peña procuró, como secretario de la Comisión Nacional del Centenario, que el gobierno diera participación y recursos a la Junta. Puso a su revista Atlántida a disposición de sus colegas, lo mismo que al local del Ateneo Nacional (1913), para que pudieran dar allí conferencias públicas. Además, propuso ya en 1917 - como un antecedente de las Juntas Filiales- que se formaran centros de estudios en las provincias. ${ }^{26}$

Por los temas de sus disertaciones y por las acciones que promovieron, ${ }^{27}$ no puede decirse que estos tres intelectuales significaran una presencia «santafesina» en la Junta, o que hayan actuado como «cuerpo» por su origen común. Los vínculos privados entre ellos venían de lejos, y habían coincidido en Santa Fe en publicaciones periódicas y comisiones culturales. Pero también habían cultivado afinidades con otros intelectuales del país, y de Buenos Aires en particular, necesarias para su admisión en una institución cerrada y elitista como lo era la Junta. De modo que al momento de actuar en ésta, habían adquirido una figura «nacional», y parecían haberse alejado de los tópicos santafesinos.

Distinto es el caso de Ramón Lassaga, que como correspondiente detentaba, él sí, una membresía genuinamente provinciana. A principios del siglo XX, era reconocido como la figura máxima de la historiografía santafesina, y el hecho de que fueran muy pocos los correspondientes en el interior (sólo 5 en 1901) es un indicador de que su obra no había pasado desapercibida para los principales historiadores del país.

El perfil de estos primeros santafesinos que ingresaron a la JHNA, en una etapa previa a la de profesionalización, fue el del productor cultural que conjugaba sus intereses intelectuales con su actuación pública y el ejercicio de la abogacía. Las motivaciones del presente no se habían desprendido de su práctica historiográfica, y no demostraron ser sistemáticos en sus investigaciones. Sus obras de carácter histórico, que aparecen combinadas con otros géneros literarios, son reflejos de una etapa en la que aún la Historia no se había configurado como campo autónomo.

Puede sostenerse empero que, más allá de sus múltiples ocupaciones, su pertenencia a la JHNA ayudó a configurar la imagen de «historiadores» que les ha adjudicado la historiografía posterior, que los ha consagrado como los principales referentes de la disciplina en la Santa Fe de entresiglos.

26 BJHNA, V, 198-200 y 244, y VII, 1930, 405.

27 El análisis de la participación de estos intelectuales en la JHNA, en: Micheletti, 2011. 


\section{Los nombramientos de 1915 y la apertura hacia el interior}

Si bien, para el caso de Santa Fe, la membresía de Ramón Lassaga significó la proyección de la JHNA en la provincia y la prueba de que ésta había sido concebida como una institución «nacional», ese cometido se cumplió en muy pequeña medida en los primeros años. Hasta 1914, habían sido incorporados tan sólo siete correspondientes de todo el país a la Junta.

Fue a Martiniano Leguizamón, a quien se debió en 1915 la iniciativa de impulsar el nombramiento de correspondientes. Al presentar su proyecto, Leguizamón realizó una revalorización de los historiadores provinciales, interesante por la época temprana en que lo hizo. Se refirió al aislamiento y escasez de recursos con los que trabajaban, rescató su aporte al revisar los archivos provinciales, aludió al móvil reivindicatorio que solía guiar su labor, y los defendió de los juicios peyorativos que se vertían sobre ellos desde la capital del país y que minimizaban sus aportes debido al alcance local de sus estudios..$^{28} \mathrm{La}$ incorporación fue presentada como un estímulo, y como una manera de difundir investigaciones que de lo contrario quedaban «inéditas o extraviadas en publicaciones exóticas y de escasa circulación». ${ }^{29}$

La lista presentada por Leguizamón incluía a siete historiadores, acompañados de su respectiva bibliografía. Entre ellos figuraba Juan Álvarez, entrerriano radicado desde niño en Rosario. El proyecto fue bien recibido y aprobado, de modo que el número de correspondientes aumentó repentinamente en 1915, agregándose algunos más al año siguiente.

Dentro de esta ola de incorporaciones, fueron nombrados correspondientes, entre 1915 y 1916, Bernardo Frías (por Salta), y Martín Ruiz Moreno y Benigno Tejeiro Martínez (por Entre Ríos), exponentes los tres de la línea reivindicatoria de caudillos locales mencionada antes, por lo que sus obras pueden considerarse en sintonía con las de Lassaga y Peña. ${ }^{30}$

En cuanto a Álvarez, era autor de varios libros. Orígenes de la música argentina y Estudio sobre las guerras civiles argentinas fueron los mencionados por Leguizamón. Llamativamente, éste omitió mencionar el libro

28 El menosprecio hacia los historiadores provinciales, que Leguizamón advertía en 1915, se haría explícito en la primera historia de la historiografía argentina elaborada una década más tarde por Rómulo Carbia: éste los agrupaba bajo el «género menor» de «cronistas regionales» y a su producción no la consideraba relevante. Carbia, 1940, 171-185.

29 BJHNA, VI, 1929, 295-296.

30 Frías defendió a Martín de Güemes, y Ruiz Moreno y Tejeiro Martínez, a Francisco Ramírez. Además, el último había reivindicado a Artigas desde principios de los ' 80 . 
que lo revelaba como un historiador regional: el Ensayo sobre la historia de Santa Fe (1910). ¿La explicación de ello?: si se atiende al juicio de algunos analistas, su Ensayo tuvo poca repercusión en su momento por sus características precursoras, y fue valorado sólo años después. ${ }^{31}$

Álvarez compartía, con los intelectuales rosarinos que se habían incorporado a la Junta en los primeros años, algunos rasgos que iban más allá de la profesión jurídica en común, ya que su producción era conocida y estimada en Buenos Aires y superaba los límites de la crónica regional. Se distanciaba de ellos, empero, por su concepción de la Historia, en la que adjudicaba un rol fundamental al factor económico (Álvarez ha sido considerado el fundador de la historia económica argentina). En el Ensayo, por ejemplo, consideraba que el autonomismo defendido por Estanislao López era consecuencia de la necesidad, ya que sólo en el aislamiento Santa Fe podía reorganizar su economía vapuleada por las guerras civiles; ${ }^{32}$ una interpretación muy distinta a la de Ramón Lassaga, quien había realizado una lectura épica a partir de la figura de un «gran hombre». ${ }^{33}$ Por esas características innovadoras, Álvarez se constituyó en un referente para ciertos sectores intelectuales de entonces y de generaciones posteriores.

También puede llamar la atención que Leguizamón no incluyera en el listado a Manuel Cervera, autor de la primera historia integral santafesina: Historia de la ciudad y provincia de Santa Fe (1907), pero esto puede explicarse por la menor proyección de su obra en los círculos porteños.

$\mathrm{Al}$ año siguiente de la incorporación de Álvarez era designado otro rosarino, pero como numerario. Destacado jurista y profesor universitario, Rodolfo Rivarola se encontraba entre los intelectuales argentinos más reconocidos de entresiglos. Fue el fundador de la Revista de la Universidad de Buenos Aires, de la Revista Argentina de Ciencias Políticas, y de la Academia Nacional de Ciencias Morales y Políticas. Entre sus libros de carácter histórico se encontraban: Partidos políticos, Unitario y Federal, Ensayo de Política (1905) y Del régimen federativo al unitario (1908), que lo mostraban partidario del unitarismo, un posicionamiento que podría parecer extraño para un historiador proveniente del Litoral, pero que puede

31 Como señala Oscar Videla, Álvarez basaba la explicación de la historia en factores generales —en particular, económicos—, que relegaban a segundo plano a los individuos y rompían con la imagen del «grande hombre». Videla, 2005. Para Enrique Barba, el Ensayo parecía un «libro insólito» en el momento de su aparición, caracterizado por el culto del héroe y por un elevado sentimiento de orgullo nacional. Citado en: Bazán, 1998, 146.

32 Devoto y Pagano, 2009, 120.

33 Un estudio detallado sobre la obra de Lassaga en: Micheletti, 2010. 
explicarse tanto por su prolongada permanencia — desde los años estudiantiles- en Buenos Aires, como por la crisis que sufría por entonces el sistema federal. ${ }^{34}$ Sus conferencias en la Junta poco tendrían que ver con la historia de su provincia, una temática alejada de aquellas que concitaban su interés, centradas en las relaciones entre historia, filosofía y ciencia política.

Tanto las obras de Álvarez como las de Rivarola eran reflejo de un clima de época de entresiglos signado por el positivismo, o por lo que Oscar Terán ha denominado «cultura científica». ${ }^{35}$ La actuación en ámbitos universitarios, la apertura hacia nuevos enfoques —que en el caso de Álvarez se orientarían, sobre todo, a la consideración del factor económico y, en el de Rivarola, estrecharían los nexos con la filosofía y la ciencia política- - y la búsqueda de explicaciones generales, fueron algunos de los rasgos que caracterizaron una nueva actitud, de base científica, para el abordaje del pasado. ${ }^{36}$ Ejemplifica esa actitud una conferencia de Rivarola en la que, influenciado por el positivismo espiritualista de Alfred Fouillée, pretendía probar la existencia de ciclos de ideas-fuerzas en la historia argentina. ${ }^{37}$

En cuanto a la incidencia en el campo de la historia provincial, si bien las circunstancias en las que se produjo el nombramiento de Álvarez obedecieron a un impulso de apertura de la Junta hacia el interior, éste no se consolidó por entonces en una experiencia más sostenida de vinculación con los ámbitos provincianos de producción historiográfica, ni la membresía de Álvarez y Rivarola pareció aportar por esos años nuevos contenidos, de alcance regional, a las temáticas puestas a consideración en la Junta.

\section{El reconocimiento a la historiografía santafesina}

En 1925 se produjo una nueva oleada de incorporaciones de historiadores provinciales. A la sazón, era presidente de la Junta Martiniano Leguizamón, que de nuevo propició el nombramiento de correspondientes. Así, entre 1923 y 1927 — período que duró su presidencia- fueron designados 22 correspondientes, alcanzándose en 1925 un máximo de 14 designaciones.

34 Buchbinder, 2005, 31.

35 Para Terán, la expresión «cultura científica» designa al conjunto de intervenciones teóricas que reconocen el prestigio de la ciencia como dadora de legitimidad de sus propias argumentaciones. Terán, 2008.

36 Devoto y Pagano, 2009, 73-81.

37 Rivarola, 1931, 133-158. 
Por Santa Fe fueron incorporados ese año dos historiadores que, aunque nacidos fuera de los límites provinciales, fueron santafesinos por adopción: Manuel Cervera y Félix Barreto. Este último, periodista e historiador, autodidacta, era director de la biblioteca de la Casa de Gobierno y organizó el Archivo histórico de la provincia. La temática santafesina predominaba en su producción, como es fácil suponer en alguien que pasaba sus días en los archivos provinciales. Luego de Iriondo, era el primer santafesino que ingresaba a la Junta sin ser abogado. Manuel Cervera, en tanto, era la principal figura de la historiografía provincial. Su Historia de la ciudad y provincia de Santa Fe superaba con creces, por su amplitud cronológica y temática, cuanto se hubiese escrito sobre historia santafesina.

Estos dos nombramientos tenían el valor de incorporar a la Junta a historiadores cuya obra se concentraba en el estudio del pasado de Santa Fe y cuyo desempeño público era santafesino. Significaban la continuación, en este sentido, de Ramón Lassaga — ya fallecido-, y su designación implicaba un reconocimiento externo a una producción que hasta entonces había sido sobre todo leída y valorada dentro de los límites provinciales. Ese reconocimiento encontraba su parangón, también en 1925, en el juicio de un analista ajeno a la Junta pero integrante del Instituto de Investigaciones Históricas y representante de la NEH. Rómulo Carbia, en su Historia de la historiografía argentina, aún cuando incluía a la obra de Cervera en el género menor de la crónica regional, la distinguía como caso de excepción, por su copiosa documentación, su erudición y su atención a diversos aspectos que la hacían iniciadora en el país de la «historia integral». ${ }^{38}$

De ninguno de estos dos historiadores se conocen conferencias pronunciadas en la Junta, lo que nos priva de saber qué temas hubiesen elegido para dar a conocer en el ámbito de esta institución «nacional». Fue gracias a algunos historiadores de otras provincias, incorporados por la misma época, que los tópicos provincianos — hasta entonces esporádicos- cobraron mayor cuerpo en el recinto de la Junta. Los santafesinos se mantuvieron en sus disertaciones, por el momento, ajenos a ese movimiento que buscaba ubicar en el eje del análisis a temáticas de carácter local. ${ }^{39}$

38 Carbia, 1940, 182-183.

39 La única exposición brindada por esos años por uno de los correspondientes por Santa Fe, Juan Álvarez, se ocupó de «El factor individual en la historia» (1928), y si bien su autor apelaba a ejemplos extraídos de documentos provinciales, intentaba ensayar una interpretación más general sobre el acontecimiento histórico. Álvarez, 1928, 139-146. 


\section{La Junta Filial de Rosario y el giro hacia la historia local}

La proyección de la Junta hacia el interior adquirió mayor realidad a partir de 1926, al tomarse la decisión de instalar Juntas Filiales..$^{40}$

En 1928 quedó constituida la Junta Filial de Córdoba, ya durante la presidencia de Levene y, en 1929, la de Rosario. No es casual que las filiales se instalaran en esas ciudades. Córdoba poseía, de lejos, la mayor cantidad de correspondientes ${ }^{41}$ Rosario había provisto a la Junta varios miembros de número, y contaba con un reconocido correspondiente, Juan Álvarez, que sería el primer presidente de la Junta local. El objetivo de estas creaciones era el de «fomentar los estudios históricos y propender al intercambio de ideas y elementos para la investigación». ${ }^{42}$

El 17 de agosto de 1929, la Junta aprobó la instalación de la filial Rosario bajo la presidencia de Álvarez, y nombró como secretario a Nicolás Amuchástegui. El 28 de septiembre se completó el plantel, con Antonio Cafferata, Julio Marc, Calixto Lassaga y Francisco Santillán. ${ }^{43}$ Días más tarde tuvo lugar el acto de asunción de los cargos, presidido por Levene.

Los discursos pronunciados dieron cuenta de la tensión existente en el imaginario de la sociedad, entre el «ser» de una ciudad volcada a los negocios, y un «deber ser» que reclamaba mayor atención para el intelecto. Según Amuchástegui, la instalación de la Filial demostraba que dicha tensión estaba en vías de solución y que Rosario, además de ser un emporio mercantil, podía ser un centro de irradiación cultural. Levene también hizo referencia al carácter bifronte de Rosario: «gran ciudad, vibrante por su capacidad para la acción y por su poder intelectual». ${ }^{44}$ Juan Álvarez, a su turno, se hizo portavoz de un discurso localista que resaltaba los aportes de Rosario a la nación, e instó a los historiadores lugareños a complementar o brindar visiones alternativas a las versiones de la historia en circulación. Con cierto decadentismo, exaltaba el rol jugado por Rosario en el pasado:

Hace falta que el Rosario recuerde su pasado; que recordándolo, suministre nuevos puntos de vista al estudio de la Historia Argentina; y que advirtiendo el rol que desempeñó antes, comprenda bien cuál es el que debe desempeñar en el futuro. Para

40 Girbal-Blacha, 1995, I, 103.

41 En 1927 había 31 correspondientes; 6 eran cordobeses. Girbal-Blacha, 1995, I, 105.

42 BANH, XIX, 1946, 542.

43 Ibidem, 546-548.

44 BJHNA, VI, 325, y 330-331. 
lograrlo, se funda hoy aquí una institución cuyo único objeto es revelar lo que fue el pasado y hacerlo valer ante los ojos del presente. Ha correspondido a la JHNA prestar al Rosario el valiosísimo servicio de ayudarla a reconstruir ante la República entera su conciencia de gran ciudad y de importantísimo elemento para el equilibrio interno nacional $[\ldots] .45$

Con estas palabras, Álvarez marcaba un rumbo y definía el estilo de los estudios que se llevarían adelante en la Filial. La preocupación por lo local sería su sello distintivo, junto con el esfuerzo por subrayar el concurso prestado a la nación por la urbe y su región —utilizando para ello, cabe aclarar, la tribuna local de una prestigiosa institución de alcance nacional-

Paralelamente a la creación de la Filial Rosario, fue incorporado en 1929 a la JHNA, como correspondiente por Santa Fe, José Luis Busaniche, abogado y autor de Estanislao López y el federalismo del Litoral.

En los años siguientes, continuaron los nombramientos para completar la integración de la Filial Rosario. En 1932 fue designado el anciano militar Federico Zeballos, hermano de Estanislao, por entonces ya fallecido. En 1936, fueron incorporados Juan Jorge Gschwind (en reemplazo de Antonio Cafferata, fallecido en 1932) y Faustino Infante.

Entre los nombrados en Rosario había hombres con fuertes vinculaciones políticas y sociales, como Marc, Zeballos o Cafferata, y otros de orígenes más modestos, en quienes la actividad intelectual había servido como instrumento de promoción social, como Santillán o Gschwind.

Todos los nombrados eran abogados, a excepción del pedagogo Santillán, del publicista Gschwind y de F. Zeballos, y la mayoría había ocupado y ocuparía cargos públicos municipales y provinciales. Compartían el interés por el pasado local, y varios habían integrado en 1925 la Junta Ejecutiva Pro Festejos del Segundo Centenario de la Fundación del Rosario. Además, algunos intervinieron en la concreción de instituciones orientadas a resguardar la cultura y memoria rosarinas, como la Comisión Municipal de Bellas Artes, y de museos que eran llevados adelante con recursos privados, expresión de una burguesía rosarina que buscaba legitimar su preeminencia como clase, y librar a Rosario de la imagen de «ciudad fenicia». ${ }^{46}$

El interés por dar vida a este tipo de instituciones era alto para los miembros de la Filial Rosario, si se tiene en cuenta que, entre sus primeras iniciativas, consideraron la organización de un Archivo Histórico en Rosario

45 Ibidem, 333.

46 Zapata y Simonetta, 2011. 
y de un Museo Sanmartiniano en San Lorenzo. ${ }^{47}$ Estos dos proyectos tendían a insertar a Rosario y su área de influencia en el circuito de la cultura nacional y a historizar su evolución temporal, al dotarla de instituciones que contribuirían a resaltar su protagonismo en el proceso histórico argentino. El ejemplo del proyectado Museo - que no se concretó por entonces-es ilustrativo, ya que buscaba capitalizar para la región — que portaba el estigma de carecer de pasado - el título de haber sido escenario de la victoriosa, primera y única batalla del general San Martín en suelo patrio.

Esa operación se reflejó también en los temas elegidos para las conferencias, que ahondaron en aquellos contados episodios en los que la tradición historiográfica argentina había rescatado el nombre de Rosario. En un ciclo de conferencias realizado en la Filial entre 1930 y 1931, C. Lassaga se refirió a la mayor gloria de la historia rosarina, centrándose en determinar el sitio en el que había sido izada por primera vez por Manuel Belgrano la bandera nacional. Santillán, por su parte, abordó el mentado suceso del incendio de Rosario por parte del general Balcarce, planteando dudas sobre su veracidad. ${ }^{48}$ A juzgar por la interpretación esbozada por los historiadores rosarinos, la localización espacial contribuía a atribuirle significación al hecho, como si un determinismo geográfico señalara a Rosario como campo propicio para sucesos memorables. En este sentido, C. Lassaga aludía a los «grandes y trascendentales acontecimientos ocurridos dentro de una pequeña zona de territorio argentino, bordeada por el caudaloso Paraná, en la cual está el Rosario». La conferencia de Lassaga, además, presentaba una arista pragmática: obtener el concurso de la JHNA a fin de erigir un monumento que convirtiera el sitio del izamiento en un lugar de memoria. ${ }^{49}$

Dentro de este marco general de análisis, algunos miembros optaron por rescatar del olvido a personajes y sucesos menos conocidos del pasado local, esforzándose por mostrar la pertinencia de su inclusión en las grandes páginas de la historia nacional. Esta postura historiográfica tendía a colocar en un mismo plano a los hechos del pasado local que ella sacaba a la luz, con aquellos destacados por la historia argentina, reduciendo las diferencias a una mera cuestión de casualidad o fortuna dentro del trabajo heurístico del historiador de antaño, de modo que había «héroes» que, aunque merecían «una página del libro donde se recuerda a los que fueron, en su hora, abnegados servidores de la patria», permanecían ignotos, tan sólo

47 BJHNA, VI, 3. Príncipe y Montini, 2009.

48 Santillán, 1930, 207-224.

49 Lassaga, 1930, 197-198. 
porque les «faltó la mano del cronista amigo que sacudiera el polvo de los legajos». ${ }^{50}$

Un tercer núcleo temático retomaba aquellas cuestiones vinculadas a la etapa de los caudillos y de las guerras civiles, orientadas a poner de relieve la política autonómica santafesina, que enlazaban con los estudios precursores del siglo XIX, y que ahora se producían en el marco de un clima que recogía los aportes de la NEH —en particular, los de Emilio Ravignani sobre el caudillismo y el federalismo- $-{ }^{51}$ y que anunciaba el revisionismo histórico de los años treinta, es decir, un escenario más proclive que aquellos tan marcados por la historiografía liberal.

José Luis Busaniche fue el primer santafesino que llevó estos temas a la JHNA, al referirse en su conferencia de incorporación a la política interprovincial entre 1829 y 1831 . Poco después, con motivo del Centenario de la Constitución de la República Oriental del Uruguay, leyó dos nuevos trabajos, en la Filial Rosario. Para Busaniche, la «región del Litoral» había sido «escenario de las grandes soluciones nacionales en la historia política de la República» y, el período de 1814 a 1820, «uno de los más movidos y fecundos de nuestra historia». Su relato asumía la forma de un alegato, que procuraba librar a Artigas de la imagen adversa que le había atribuido la historiografía, y demostrar que el caudillo oriental estaba en el origen del sistema federal argentino que se impuso en la Constitución de 1853.52

En cuanto a filiaciones historiográficas, se advierte en estos autores una constante alusión a Mitre, a veces como apoyatura y, otras, para indicar silencios o errores que debían subsanar. ${ }^{53}$ Pero también hay referencias a autores provinciales, como Carrasco, Zeballos, Cervera y Álvarez. Para legitimar su posición, Busaniche recurrió a la autoridad de Ravignani, ${ }^{54}$ por una sintonía de ideas que no hallaba en otros referentes de la NEH. ${ }^{55}$

La Filial Rosario desplegó durante la década del ' 30 una serie de actividades orientadas a impulsar en la ciudad el estudio y difusión de temas históricos, y dio apoyo institucional a diversas conmemoraciones rosarinas.

50 Cafferata, 1929, 179.

51 Ravignani encontró compatibles las ideas de autonomía provincial y unidad nacional de los caudillos, y los ubicó en la génesis del sistema constitucional. Buchbinder, 2005, 43-46.

52 Busaniche, 1930, 245-246 y 249.

53 Lassaga, 1930, 199; Busaniche, 1930, 262; Santillán, 1930, 208-209 y 222; y Cafferata, 1929,180 y 182.

54 BJHNA, VII, 251.

$55 \mathrm{Si}$ el constitucionalismo de Ravignani se centraba en la configuración del Estado federal, la línea de Levene ponía, como Mitre, el acento en Mayo. Devoto y Pagano, 2009, 168-169. 


\section{La Junta de Santa Fe y la consolidación de los vínculos}

En 1935, Juan Álvarez fue elevado a la categoría de miembro de número. Para su incorporación, eligió un tema que lo posicionaba de lleno en el plano de la historia local: «Rosario bajo el gobierno autónomo de Estanislao López». Si hasta ese momento, la historia rosarina no había salido del ámbito de la Filial Rosario, ahora Álvarez la trasladaba al centro de la discusión historiográfica académica. Elegía para tratarla, el período de mayor interés para la tradición santafesina, si bien desde un punto de vista distinto al de los historiadores de la capital provincial, como R. Lassaga y J. L. Busaniche. La situación de postergamiento político y económico sufrida por Rosario frente a una capital que la expoliaba y la puja de intereses entre el norte y el sur provincial - leit motiv que atraviesa su Historia de Rosario (1943) - eran anticipadas en su conferencia de 1936 en la Junta. ${ }^{56}$

El nombramiento de Álvarez como numerario se completó en 1936 con el de un nuevo correspondiente por Santa Fe: el sacerdote jesuita Guillermo Furlong, un historiador erudito que estudió la historia social y cultural del Río de la Plata, y realizó aportes en geografía histórica.

La Junta intensificaba, en tanto, su vinculación con las provincias, auspiciando la formación de centros. En Entre Ríos quedó constituida una Filial, y se estableció una nueva categoría, la de las Juntas Adheridas, entre las que se incluyeron las de Mendoza y San Juan. En 1936 se formó la Junta de Estudios Históricos de Santa Fe, presidida por Cervera. ${ }^{57}$ Organizada con una estructura similar a la JHNA, los contactos entre ambas fueron fluidos. ${ }^{58}$ Sus integrantes hicieron suyos los postulados de la Nueva Escuela Histórica, y colaboraron - bien que desde una posición periférica- en la Historia de la Nación Argentina dirigida por Levene..$^{59}$ Estas Juntas, surgidas previamente a la organización de la enseñanza superior en Historia en las provincias, reunían a aficionados, profesionales de otras disciplinas y miembros del clero, y mantenían vinculaciones estrechas con los gobiernos locales.

56 Álvarez, 1937, 11-24.

57 Coudannes Aguirre, 2005.

58 Revista de la Junta de Estudios Históricos de Santa Fe, 1, Santa Fe, 9 de julio de 1936, 9.

59 Pese a los intentos de Levene, la idea de brindar una visión argentina integral del pasado se mostró difícil, tal como quedó demostrado con los tomos de «historia de las provincias» que, a manera de «anexo», se agregaron al final de la colección. 
El objetivo de incrementar los nexos con los ámbitos provinciales de producción historiográfica se puso de manifiesto en el respaldo que la JHNA le otorgó al Congreso de Historia de Cuyo (1937), del cual Levene tomó la idea de realizar los Congresos de Historia regional y nacional.

$\mathrm{Al}$ año siguiente, fue la Junta de Santa Fe la que organizó un evento con motivo del centenario de la muerte de Estanislao López. Si los actos organizados en 1886 al cumplirse el centenario del nacimiento del caudillo - en los que habían intervenido R. Lassaga y D. Peña- no despertaron eco en las autoridades nacionales ni en figuras destacadas de la intelectualidad argentina, las Jornadas de Estudios Históricos de 1938 recibieron delegaciones de gobiernos provinciales, universidades e instituciones de diversos puntos del país y gozaron de la presencia prestigiadora del vicepresidente de la Nación y del presidente de la - ya para entonces- Academia. ${ }^{60}$ Esa diferencia, por un lado, daba la medida de lo que se había avanzado, durante ese medio siglo, en cuanto a institucionalización de la disciplina histórica a nivel nacional y provincial, y en lo relativo a la constitución de vínculos y redes entre quienes la cultivaban en diversos puntos del país. Por otro lado, era reflejo de un clima de ideas, que alentaba la realización de nuevas lecturas sobre la época de las guerras civiles y sobre las relaciones entre la nación y las provincias. En el homenaje de «justicia histórica» rendido a López en 1938, Levene remarcó la significación de Santa Fe como propagadora de la Revolución de Mayo y destacó el rol de López en la firma de los pactos que sirvieron de base para la organización constitucional. ${ }^{61}$ En el discurso del presidente de una de las principales instituciones dedicadas a la Historia, los santafesinos podían encontrar el reconocimiento que desde fines del siglo XIX venían reclamando al aporte realizado por su provincia a la construcción de la nacionalidad argentina.

\section{Consideraciones finales}

Durante las cuatro décadas comprendidas entre la creación de la JHNA y su reconversión en Academia, la escritura de la historia en la

60 Micheletti, 2007, y Tedeschi, 2004.

61 «Jornadas Históricas en homenaje al brigadier Estanislao López. Discurso del presidente de la Academia, Dr. Ricardo Levene», BANH, XII, 1939, 479-481. 
Argentina experimentó cambios significativos. El avance de la profesionalización, acompañada de un proceso de institucionalización del saber histórico, así como el surgimiento de nuevos clivajes político-ideológicos desde los cuales buscar comprender el pasado, posibilitaron la aparición de diversos ámbitos de discusión historiográfica. De entre ellos, la Junta continuó representando la vertiente más liberal y conservadora, que desde 1938 estaría bajo la tutela del Estado. Pero aún así, dio acuse de esas transformaciones, que en lo que hace al tema de este trabajo se evidenciaron en una más detenida atención a los historiadores y espacios de producción provinciales, así como a sus argumentos o claves interpretativas del pasado.

Si los primeros santafesinos de la Junta llegaron a ella casi a costa de desprenderse de su atuendo provinciano y gracias a interactuar en círculos porteños, y poco introdujeron los temas de su provincia, las generaciones sucesivas lograron inyectar en la corporación tópicos y miradas santafesinas de la historia nacional, auxiliados por un marco institucional que fomentó su agrupamiento y que dio cabida —en su sala de conferencias y en su Boletín - a esas lecturas regionales. Para 1938, poco quedaba del «aislamiento» al que se había referido en 1915 Leguizamón para caracterizar el modo de hacer historia en las provincias, y a esta conclusión abona una interesante literatura desarrollada en años recientes en torno a las historiografías provinciales, develando prácticas y condiciones de producción. ${ }^{62}$ En lo que respecta a Santa $\mathrm{Fe}$ - la provincia que tuvo la mayor cantidad de miembros correspondientes- ${ }^{63}$ desde la Filial Rosario y desde la Junta de Estudios Históricos, sus miembros desplegaban por entonces una mancomunada, entusiasta y sostenida labor de rescate y difusión del pasado local y regional.

Recibido el 15 de septiembre de 2011 Aceptado el 24 de julio de 2012

62 Se posee el objetivo de avanzar hacia un análisis comparativo de los miembros de la Junta provenientes de distintas provincias, a fin de determinar peculiaridades y afinidades. Por el momento, se dispone de estudios limitados a diversos espacios provinciales que pueden ser puestos en relación. Entre otros, para el caso del Nordeste, son muy sugestivos los trabajos de María Silvia Leoni y María Gabriela Quiñónez, como los incluidos en: Maeder et. al, 2004; para Santa Fe, la reciente compilación de Suárez y Tedeschi, 2009; para Córdoba, Moreyra, 2002; para Salta, Quiñónez, 2003.

63 Entre 1893 y 1938, Santa Fe tuvo 14 correspondientes, seguida por Córdoba, con 13. 


\section{Bibliografía}

Abad de Santillán, Diego: Gran enciclopedia de la provincia de Santa Fe, Buenos Aires, Ediar, 1967.

Academia Nacional de la Historia (ANH): La Junta de Historia y Numismática Americana y el movimiento historiográfico en la Argentina (1893-1938), I, Buenos Aires, 1995.

Álvarez, Juan: «El factor individual en la Historia», Boletín de la Junta de Historia y Numismática Americana (BJHNA), V, 1928, 139-146.

Álvarez, Juan: «Rosario bajo el gobierno autónomo de Estanislao López (Desde 1822 hasta 1838) », BJHNA, X, 1937, 11-24.

Bazán, Armando Raúl: «Juan Álvarez y su interpretación renovadora de la Historia Argentina», Investigaciones y Ensayos, 48, Buenos Aires, ANH, 1998, 139-152.

Boletín de la ANH (BANH), XI-XIX, 1938-1946.

Boletín de la Junta de Historia y Numismática Americana (BJHNA), II-X, 19251930 y 1936-1937.

Buchbinder, Pablo: «Caudillos y caudillismo: una perspectiva historiográfica», en Goldman, Noemí y Salvatore, Ricardo (comps.): Caudillismos rioplatenses. Nuevas miradas a un viejo problema, Buenos Aires, Eudeba, 2005, 31-50.

Busaniche, José Luis: «Artigas en los orígenes autonómicos de Santa Fe», BJHNA, VII, 1930, 245-264.

Cafferata, Antonio: «Don Celedonio Escalada», BJHNA, VI, 1929, 179-194.

Carbia, Rómulo: Historia crítica de la historiografía argentina, Buenos Aires, Coni, 1940.

Coudannes Aguirre, Mariela: «La historiografía santafesina y los usos del pasado en la década del treinta», X Jornadas Interescuelas / Departamentos de Historia, Rosario, 2005 (CD).

Devoto, Fernando y Pagano, Nora: Historia de la historiografía argentina, Buenos Aires, Sudamericana, 2009.

Dumoulin, Olivier: Le rôle social de l'historien. De la chaire au prétoire, Paris, Albin Michel, 2003.

Gallo, Ezequiel: La pampa gringa: la colonización agrícola en Santa Fe, 18701895, Buenos Aires, Sudamericana, 1983.

Girbal-Blacha, Noemí: «La aproximación al cambio, el dinamismo interno y la transición hacia la apertura intelectual», ANH, 1995, I, 95-121.

Lassaga, Calixto: «Determinación del sitio en que se izó por primera vez la bandera argentina», BJHNA, VII, 1930, 197-206.

Maeder, Ernesto, et. al.: Visiones del Pasado. Estudios de Historiografía de Corrientes, Corrientes, Moglia ediciones, 2004.

Micheletti, María Gabriela: «El centenario de Estanislao López en 1886 y la reivindicación de Santa $\mathrm{Fe}$ en la historia nacional», en XI Jornadas 
Interescuelas / Departamentos de Historia, Tucumán, Universidad Nacional del Tucumán, 2007 (CD).

Micheletti, María Gabriela: «Los niveles de la memoria: la nación, la provincia y la ciudad en la visión de tres responsables de la educación de fines del siglo XIX en la cosmopolita Santa Fe argentina», Antíteses, II-3, Universidad Estadual de Londrina/PR - Brasil, 2009, 67-92 (http://www.uel.br/revistas/ uel/index.php/antiteses/article/view/2007/2186).

Micheletti, María Gabriela: «Primeros esfuerzos historiográficos en defensa de las provincias y sus caudillos: la Historia de López, de Ramón Lassaga», Revista de la Escuela de Historia, 9, Salta, Universidad Nacional de Salta, 2010, 91-118.

Micheletti, María Gabriela: «Los primeros santafesinos de la Junta de Historia y Numismática Americana. Consideraciones en torno a la personalidad y labor de cuatro intelectuales notables.», Revista de la Junta Provincial de Estudios Históricos de Santa Fe, 69, Santa Fe, 2011, 75-104.

Mitre, Bartolomé: Historia de Belgrano y de la Independencia argentina, Buenos Aires, Eudeba, 1967, vol. I

Moreyra, Beatriz (comp.): La Escritura de la Historia. Una mirada sobre las prácticas y los discursos de los historiadores de Córdoba (Argentina), Córdoba, Centro de Estudios Históricos «Prof. Carlos S. A. Segreti», 2002.

Pasamar Alzuria, Gonzalo y Peiró Martín, Ignacio: «La "vía española” hacia la profesionalización historiográfica», Studium, 3, Teruel, 1991, 135-162.

Peiró Martín, Ignacio: «La historiografía académica en la España del siglo XIX», Memoria y Civilización, 1, Pamplona, 1998, 165-196.

Peña, David: Juan Facundo Quiroga. Contribución al estudio de los caudillos argentinos, Buenos Aires, Coni Hermanos, 1906.

Peña, David: «Juan Facundo Quiroga, Origen del "Facundo"», Revista de Derecho, Historia y Letras, XXIV, 1906, 498-513.

Pompert de Valenzuela, María Cristina: «El Instituto de Investigaciones Históricas de la Facultad de Filosofía y Letras de la Universidad de Buenos Aires», en ANH, 1995, I, 251-270.

Príncipe, Valeria y Montini, Pablo: «El Museo Sanmartiniano y la Junta de Historia y Numismática, Filial Rosario», en Broda, Vanina, et al (coords.), $V$ Jornadas Nacionales Espacio, Memoria e Identidad, Rosario, Universidad Nacional de Rosario, 2009 (CD).

Quiñónez, María Mercedes: «Bernardo Frías y la "Historia del General Güemes". El contexto de recepción de una obra fundante de la historiografía salteña», IX Jornadas Interescuelas/Deptos. de Historia, Córdoba, 2003.

Ravina, Aurora: «La fundación, el impulso mitrista y la definición de los rasgos institucionales», en ANH, 1995, I, 23-59.

Revista de la Junta de Estudios Históricos de Santa Fe, 1, Santa Fe, 9 de julio de 1936. 
Rivarola, Rodolfo: «Ciclos de ideas-fuerzas en la Historia Argentina», BJHNA, VIII, 1931, 133-158.

Sánchez-Prieto, Juan María: «Los correspondientes navarros en la Real Academia de la Historia (1833-1900)», Príncipe de Viana, 180, Pamplona, 1987, 193-226.

Santillán, Francisco: «¿Fue incendiada la "Capilla del Rosario”?», BJHNA, VII, 1930, 207-224.

Suárez, Teresa y Tedeschi, Sonia (comps.): Historiografía y sociedad, Santa Fe, Universidad Nacional del Litoral, 2009.

Tedeschi, Sonia: «La vocación de memoria en los homenajes: Justicia al mérito», Anuario de la Escuela de Historia, 20, Rosario, 2004, 237-262.

Terán, Oscar: Vida intelectual en el Buenos Aires fin-de-siglo (1880-1910). Derivas de la «cultura científica», Buenos Aires, FCE, 2008.

Vázquez, Josefina: «Cincuenta y tres años de las Memorias de la Academia Mexicana de la Historia», Historia Mexicana, L-4, México DF, 2001, 709-718.

Videla, Oscar: «Algunas miradas sobre la obra historiográfica de Juan Álvarez», en II Jornadas de Historia e Integración Cultural del Cono Sur, Facultad de Humanidades y Ciencias Sociales, Universidad Autónoma de Entre Ríos, Concepción del Uruguay, 2005.

Zapata, Horacio y Simonetta, Leonardo: «Las configuraciones de sentido en el Museo Histórico Provincial de Rosario a principios del siglo XX: memorias visibilizadas, actores negados y pasados en pugna», Temas de historia argentina y americana, 18, Buenos Aires, 2011, 213-251. 